\title{
Comparative study of group A and group C meningococcal infection
}

\author{
L. G. EVANS-JONES, H. C. WHITTLE, I. I. ONYEWOTU, L. J. EGLER, AND \\ B. M. GREENWOOD
}

From the Departments of Paediatrics, Medicine, and Microbiology, Ahmadu Bello University, Zaria, Nigeria

SUMMARY 114 patients with meningococcal infection were studied; 72 had group $C$ infection and 42 group $A$ infection. 14 patients had acute meningococcaemia, all of whom had group $C$ infection and 9 of whom died. Clinical and laboratory findings were similar in patients with meningitis due to group $\mathrm{A}$ and $\mathrm{C}$ organisms, but arthritis and cutaneous vasculitis were more common in patients with group $\mathrm{C}$ infection. The overall mortality was $22 \%$ in patients with group $\mathrm{C}$ infection, and $12 \%$ in patients with group A infection, but was the same in both groups when cases of acute meningococcaemia are excluded.

Epidemics of meningococcal infection occur in the northern savanna of Africa nearly every dry season. In the past these epidemics have been mainly due to infection with group A meningococci (Lapeyssonnie, 1963). Outbreaks of group B infection have been reported in the Sudan (Erwa et al., 1971) but epidemics of group C infection have not been seen. We have recently reported the emergence of group $\mathbf{C}$ meningococcal infection in this area (Whittle et al., 1975). The occurrence of cases of both group $\mathbf{A}$ and group $\mathbf{C}$ infection during the same epidemic provided an unusual opportunity for comparing the two types of infection.

\section{Patients and methods}

Patients. All patients with meningococcal infection admitted to Ahmadu Bello University Hospital, during an epidemic of meningococcal infection in January-April 1975 were studied. A diagnosis of meningococcal infection was made by culture of the meningococcus from the cerebrospinal fluid (CSF) or blood, and by the detection of meningococcal antigen in CSF or serum, or a rise in haemagglutinating antibody titre in paired sera. 72 of the 114 patients studied had group $C$ infection, 42 had group A infection. Their age distribution is shown in Table 1. Patients with group $C$ infection tended to be younger than those with group $\mathrm{A}$ infection but the difference was not significant.

Received 3 August 1976
Table 1 Age distribution of 114 patients with group $A$ or group $C$ meningococcal infection

\begin{tabular}{lllll}
\hline Group & \multicolumn{2}{l}{ Age (years) } & Total \\
\cline { 2 - 4 } & $0-4$ & $5-14$ & $15+$ & \\
\hline A & 6 & 24 & 12 & 42 \\
\hline & 23 & 37 & 12 & 72 \\
\hline
\end{tabular}

Laboratory methods. Full laboratory investigations were carried out only in patients over one year of age (6 patients only were under one year of age). CSF was examined immediately after collection by Gram stain and the cells counted. Bacteria were counted under phase-contrast microscopy using a Thoma counting chamber. Culture was carried out on Mueller Hinton medium in $5 \% \mathrm{CO}_{2}$. Samples were examined for meningococcal antigen by a latex test (Whittle et al., 1974) and counter-current immunoelectrophoresis (CIE) (Greenwood et al., 1971). Antigen titre was subsequently determined in selected CSF samples by CIE on serial dilutions of CSF, and the end-point was compared with that obtained with solutions of known group A and group C polysaccharide content. CSF protein was determined turbidometrically. CSF samples collected in bottles containing thrombin and fibrinolytic inhibitor were assayed for fibrin degradation products using a haemagglutination inhibition assay (Burroughs Wellcome). CSF samples for lactic acid determination were deproteinized by collection into bottles containing $0.6 \mathrm{~N}$ perchloric acid.

The lactic acid content of the supernatant was 
measured by an enzymic method (BoehringMannheim). Serum was tested for meningococcal antigen by CIE. Haemagglutinating antibody was measured by an indirect haemagglutination technique using sheep red cells coated with partially purified capsular antigen (Edwards and Driscoll, 1967). Blood was cultured in thioglycolate broth. Lactic acid levels in blood were measured as described above. Statistical comparisons of mean levels were by the standard ' $t$ ' test and comparisons of frequencies by the $\chi^{2}$ method.

Treatment. Patients with meningitis were treated with either benzyl penicillin $250000-500000 \mathrm{IU} / \mathrm{kg}$ per 24 hours or chloramphenicol $75-100 \mathrm{mg} / \mathrm{kg}$ per 24 hours. 45 cases of group $C$ meningitis and 18 cases of group A meningitis had chloramphenicol. 12 cases of group $\mathrm{C}$ meningitis and 16 cases of group A meningitis had penicillin. Penicillin was changed to chloramphenicol in 8 patients with group A meningitis and in 1 patient with group $C$ meningitis when parenteral therapy became undesirable. Sulphonamides were not used in view of the likelihood of sulphonamide resistance in both group A and group $\mathrm{C}$ strains.

Patients with acute meningococcaemia received parenteral penicillin or chloramphenicol in the dosage stated above, intravenous fluids, and at least one initial dose of intravenous hydrocortisone.

\section{Results}

Acute meningococcaemia. 14 patients had acute meningococcaemia without clinical or laboratory evidence of meningitis. All had group $\mathrm{C}$ infection and all were children under 10 years of age with 5 under 5 years of age. The history was of less than 24 hours' duration in all but one. Skin and conjunctival petechiae were seen in all 14 but extensive haemorrhage was not seen. 9 of the 14 were hypotensive with peripheral circulatory collapse on admission. Group $\mathrm{C}$ meningococcal antigen was present in the serum of the 14 patients on admission but blood culture was positive in 6 of the 11 patients tested. 9 patients died, all within a few hours of admission-a mortality of $64 \% .4$ of the 5 survivors developed arthritis or cutaneous vasculitis on the fifth or sixth day of their illness.

Meningitis. Table 2 summarizes the clinical findings in 58 patients with group $\mathrm{C}$ meningococcal meningitis and 42 patients with group A meningococcal meningitis. The clinical picture is similar in the two groups of patients except for a significantly higher incidence of arthritis and cutaneous vasculitis occurring on the fifth or sixth day of illness in patients with group $C$ meningitis $(P=0.02)$.

The CSF findings in both groups of patients are summarized in Table 3 . No significant difference was found in the mean cell count or bacterial count. The CSF protein was higher in patients with group A meningitis $(P=0 \cdot 02)$. Fibrin degradation products and greatly raised lactic acid levels were found in nearly all CSF samples with the mean levels similar in both groups. Individual levels did not correlate with severity or outcome of disease. As previously reported CSF lactic acid levels are independent of blood lactate levels which were only slightly raised

Table 2 Clinical features of 100 patients with meningococcal meningitis

\begin{tabular}{|c|c|c|c|c|c|c|}
\hline & $\begin{array}{l}\text { Petechiae or } \\
\text { purpura }(n)\end{array}$ & $\begin{array}{l}\text { Severe } \\
\text { neurological } \\
\text { damage }^{*}(n)\end{array}$ & $\begin{array}{l}\text { Allergic } \\
\text { complications }(n)\end{array}$ & $\begin{array}{l}\text { Average stay } \\
\text { in hospital }(d)\end{array}$ & $\begin{array}{l}\text { Permanent } \\
\text { sequelae }(n)\end{array}$ & Deaths (n) \\
\hline $\begin{array}{l}\text { Group A } \\
(n=42) \\
\text { Group C } \\
(n=58)\end{array}$ & $\begin{array}{l}16(38 \%) \\
22(38 \%)\end{array}$ & $\begin{array}{l}15(36 \%) \\
23(40 \%)\end{array}$ & $\begin{array}{c}1(2 \%) \\
10(17 \%)\end{array}$ & $\begin{array}{l}6 \cdot 3 \\
6 \cdot 2\end{array}$ & $\begin{array}{l}1 \\
1\end{array}$ & $\begin{array}{l}5(12 \%) \\
7(12 \%)\end{array}$ \\
\hline
\end{tabular}

*Unconscioushess, hemiparesis, cranial nerve palsies, or convulsions.

Table 3 CSF findings in 100 patients with group $A$ and group C meningococcal meningitis: means $\pm S D$

\begin{tabular}{|c|c|c|c|c|c|c|}
\hline & $\begin{array}{l}\text { Cell count } \\
\left(\times 10^{9} / l\right)\end{array}$ & $\begin{array}{l}\text { Bacterial count } \\
\left(\times 10^{9} / l\right)\end{array}$ & Protein $(g / l)$ & $\begin{array}{l}\text { Lactic acid* } \\
(\mathrm{mmol} / \mathrm{l})\end{array}$ & $F D P(m g / l)$ & $\begin{array}{l}\text { Meningococcal } \\
\text { antigen }(\mathrm{mg} / \mathrm{l})\end{array}$ \\
\hline $\begin{array}{l}\text { Group A } \\
(n=42) \\
\text { Group C } \\
(n=58)\end{array}$ & $\begin{array}{l}8 \cdot 4 \pm 9 \cdot 5 \\
(37) \\
5 \cdot 9 \pm 6 \cdot 3 \\
(48)\end{array}$ & $\begin{array}{l}21 \cdot 1 \pm 4 \cdot 2 \\
(26) \\
37 \cdot 7 \pm 7 \cdot 7 \\
(26)\end{array}$ & $\begin{array}{l}5 \cdot 4 \pm 4 \cdot 1 \\
(31) \\
3 \cdot 6 \pm 2 \cdot 4 \\
(46)\end{array}$ & $\begin{array}{l}13 \cdot 0 \pm 6 \cdot 7 \\
(30) \\
10 \cdot 0 \pm 0 \cdot 6 \\
(43)\end{array}$ & $\begin{array}{l}2 \cdot 9 \pm 2 \cdot 6 \\
(17) \\
2 \cdot 7 \pm 3 \cdot 2 \\
(33)\end{array}$ & $\begin{array}{l}1 \cdot 79 \pm 2 \cdot 26 \\
(12) \\
0 \cdot 6 \pm 0 \cdot 67 \\
(14)\end{array}$ \\
\hline
\end{tabular}

*Bland et al. (1974)_mean CSF lactic acid level in control group $=14 \cdot 3 \pm 0.6 \mathrm{mg} / 100 \mathrm{ml}($ conversion to $\mathrm{SI}$ units: $(\mathrm{mg} / \mathrm{l}) / 90=\mathrm{mmol} / \mathrm{l})$. FDP = fibrin degradation products.

Figures in parentheses indicate the number of investigations performed. 
in all those tested (Bland et al., 1974). The difference between the mean levels of polysaccharide antigen in the CSF of patients in the two groups was not significant. Meningococcal antigen was detected in the serum or more cases of group $\mathrm{C}$ meningitis (11 out of 58) than in the serum of patients with group A meningitis (4 out of 42) but the difference was not significant.

Mortality. The overall mortality in patients with group C infection (16 out of 72) was higher than the mortality in patients with group $A$ infection (5 out of 42). However, when the patients with acute group $\mathrm{C}$ meningococcaemia are excluded, the mortality in the two groups was identical $(12 \%)$.

\section{Discussion}

We were surprised to find that most patients with meningococcal infection in the epidemic of 1975 in Zaria had group $\mathrm{C}$ infection, as previous epidemics have been due to group A organisms. However, during the past few years we have received several samples of CSF from patients with meningococcal meningitis on the nearby Jos plateau which contained group $\mathbf{C}$ meningococcal antigen. Moreover, in other countries group $\mathrm{C}$ infection is becoming more common; for example, since about 1967 group C meningococcus has become the commonest cause of meningococcal meningitis in the USA (Artenstein et al., 1971). Recently an epidemic of group $C$ infection occurred in Brazil, an area where group A infection previously dominated (de Morais et al., 1974). Thus group $C$ meningococcus continues to extend its range and has now reached Africa.

Previous studies in the USA suggest that group $\mathrm{C}$ infection is more severe than group $\mathbf{A}$ infection (Hardman, 1968; Hardman and Earle, 1969)-our findings support this observation. 14 of our patients with group $\mathrm{C}$ infection had acute meningococcaemia while none with group $A$ infection presented in this way. Acute meningococcaemia has been very rare in much larger numbers of patients with group $A$ infection studied in previous epidemics. The mortality in patients with acute group $\mathrm{C}$ meningococcaemia was very high, death occurring within a few hours of admission. Detection of meningococcal antigen in the serum by counter-current immunoelectrophoresis was an effective and rapid way of confirming the diagnosis and was more useful than blood culture. This test is particularly valuable in the diagnosis of sporadic cases of meningococcal septicaemia in whom clinical diagnosis may be difficult.

Study of patients with meningitis showed few differences between those with group $A$ and those with group $\mathrm{C}$ infection. The incidence of neurological complications was similar and the mortality identical. Laboratory indices of meningeal inflammation were similar in the two groups. Meningococcal antigenaemia was found more fequently in patients with group $\mathbf{C}$ meningitis than in patients with group $\mathbf{A}$ meningitis. We have previously shown in patients with group A meningitis that the presence of meningococcal antigen in an initial serum sample is correlated with the subsequent development of arthritis or cutaneous vasculitis (Whittle et al., 1973), complications thought to be due to immune complex deposition in synovium and skin (Greenwood et al., 1973). It was therefore interesting to find that patients with group $\mathrm{C}$ infection had a significantly higher incidence of these complications than patients with group A infection. The arthritis and vasculitis were rarely severe and usually resolved without any specific treatment.

We have therefore found that patients with group C infection have a higher incidence of acute meningococcaemia and are therefore more likely to die than patients with group A meningococcal infection. They also have allergic complications more commonly. There are two possible explanations for these findings. It is possible that the group $\mathrm{C}$ meningococcus is naturally more virulent perhaps because of an ability to produce large amounts of endotoxin, thus causing peripheral circulatory collapse and disseminated intravascular coagulation. In a study of necropsy material, Hardman, (1968) and Hardman and Earle (1969) found evidence of acute myocarditis more commonly in patients dying of group B or C infection than in those dying of group A infection, suggesting the different virulence of the organisms (they judged acute myocarditis to be the most significant factor in the fatal outcome). Alternatively, our patients may be more susceptible to group $\mathrm{C}$ infection because of limited exposure of the community to the organism. This view is supported by the fact that all the cases of acute meningococcaemia occurred in the young and by the results of a recent serological study (unpublished) which showed much lower levels of group $\mathbf{C}$ and group $\mathbf{A}$ meningococcal antibodies in the local community. Perhaps both factors are involved.

Our findings suggest that if there is a large outbreak of group $\mathrm{C}$ meningococcal infection in this part of Africa, acute meningococcaemia will be common and the mortality will therefore be high.

We thank Mr. M. Damisah, and Miss R. M. Vick for technical help. H.C.W. and B.M.G. are in receipt of grants from the United Kingdom Medical Research Council. 


\section{References}

Artenstein, M. S., Schneider, H., and Tingley, M. D. (1971). Prevalence of serogroups causing meningococcal disease in U.S.A. army personnel (1964-1970). Bulletin of the World Health Organization, 45, 275-278.

Bland, R. D., Lister, R. C., and Ries, J. P. (1974). Cerebrospinal fluid lactic acid levels and $\mathrm{pH}$ in meningitis. American Journal of Diseases of Children, 128, 151-156.

de Morais, J. S., Mumford, R. S., Risi, J. B., Antezana, E., and Feldman, R. A. (1974). Epidemic disease due to serogroup C Neisseria meningitidis in São Paulo, Brazil. Journal of Infectious Diseases, 129, 568-571.

Edwards, E. A., and Driscoll, W. S. (1967). Group specific haemagglutination test for Neisseria meningitidis antibodies. Proceedings of the Society for Experimental Biology and Medicine, 126, 876-882.

Erwa, H. H., Satti, M. H., and Abbas, A. M. (1971). Cerebrospinal meningitis in the Sudan. Sudan Notes and Records, 52, 101-109.

Greenwood, B. M., Whittle, H. C., and Dominic-Rajkovic, O. (1971). Counter-current immunoelectrophoresis in the diagnosis of meningococcal infections. Lancet, 2, 519-521.

Greenwood, B. M., Whittle, H. C., and Bryceson, A. D. M. (1973). Allergic complications of meningococcal disease. II. Immunological investigations. British Medical Journal, 2, 737-740.
Hardman, J. M. (1968). Fatal meningococcal infections: the changing pathological picture in the sixties. Military Medicine, 133, 951-964.

Hardman, J. M., and Earle, K. M. (1969). Myocarditis in 200 fatal meningococcal infections. Archives of Pathology, 87, 318-325.

Lapeyssonnie, L. (1963). Cerebrospinal meningitis in Africa. Bulletin of the World Health Organization, 28, Suppl.

Whittle, H. C., Abdullahi, M. T., Fakunle, F. A., Greenwood, B. M., Bryceson, A. D. M., Parry, E. H. O., and Turk, J. L. (1973). Allergic complications of meningococcal disease. I. Clinical aspects. British Medical Journal, 2 733-737.

Whittle, H. C., Tugwell, P., Egler, L. J., and Greenwood, B. M. (1974). Rapid bacteriological diagnosis of pyogenic meningitis by latex agglutination. Lancet, 2, 619-620.

Whittle, H. C., Evans-Jones, L. G., Onyewotu, I., Adjukewicz, A., Turunen, U., Crockford, J., and Greenwood, B. M. (1975). Group C meningococcal meningitis in the Northern Savanna of Africa. Lancet, 1, 1377.

Correspondence to Dr. G. Evans-Jones, Department of Child Health, Alder Hey Children's Hospital, Eaton Road, Liverpool L12 2AP. 